\title{
A Novel Recycling Technology of Bamboo Using $\mathrm{NaOH}$ Kojiro Nakaaze and Takaaki Wajima \\ Graduate School of Science and Technology, Chiba University, 1-33 Yayoi-cho Inage-ku,Chiba,263-8522,Japan
}

\begin{abstract}
The bamboo industry in Japan is declined, and disordered bamboo forests are increasing. Although maintenance of bamboo forest is needed, a large amount of bamboo wastes after logging is generated and left untreated. Therefore, new utilization of bamboo wastes after logging are desired. In this research, we aimed to develop a new recycling technology for bamboo using alkali hydroxide. By pyrolyzing bamboo using hydroxide under an inert atmosphere, thermal decomposition of organic contents and alkali fusion of silica component inside the bamboo were carried out simultaneously to recover combustible gas, charcoal and silica component. The thermal decomposition behavior of bamboo, the properties of the obtained charcoal and extraction of silica in the presence of alkali hydroxide were investigated, and the optimum condition of bamboo recycling treatment was examined. As a result, it was found that when $1 \mathrm{~g}$ of bamboo was pyrolyzed at higher than $500{ }^{\circ} \mathrm{C}$ with $3 \mathrm{~g} \mathrm{NaOH}$ ,the almost silica was extracted, a large amount of gas generated, and a carbonized material with specific surface area of about more than $1100 \mathrm{~m}^{2} / \mathrm{g}$ was obtained.
\end{abstract}

Key words: Bamboo, $\mathrm{NaOH}$, Alkali fusion, Pyrolysis, Silica

\section{INTRODUCTION}

The bamboo industry has declined due to the decrease in demand and an increase in imported products. Approximately $350,000 \mathrm{~h} \alpha$ is disordered in approximately $400,000 \mathrm{~h} \alpha$ of the whole bamboo forest area in Japan. Bamboo growth is much faster than other trees, and it cause destruction of existing forests, induction of sediment collapse, damage of houses, etc. On the other hand, bamboo can be used as an effective natural resource by controlling the growth.

Bamboo is a gramineae plant that absorbs a lot of silica $\left(\mathrm{SiO}_{2}\right)$ from the ground when growing. Silica is widely used for many industry and is important resources for Japan. In previous study, silica is extracted from rice husk ash using alkali fusion method [1]. In addition, it is possible to recover charcoal, liquid and gases by pyrolysis of bamboo, and the addition of hydroxide promotes thermal decomposition of bamboo to produce the charcoal with high surface area and the high amount of gases [2], [3].

In this research, we aimed to develop a new recycling technology for bamboo using sodium hydroxide. Bamboo was heated in an inert atmosphere together with hydroxide, and thermal decomposition treatment of bamboo body and alkali fusion treatment of silica component inside the bamboo were carried out simultaneously to recover combustible gas, charcoal and silica component. The thermal decomposition behavior of bamboo, the properties of the carbonized residue and the extraction of silica in the presence of alkali hydroxide was investigated, and the optimum condition of bamboo recycling treatment was examined.

\section{EXPERIMENT}

\section{Bamboo sample}

Bamboo powder, which was collected from Chiba prefecture, Japan, was pulverized to powder with diameter of less than $3 \mathrm{~mm}$ and air-dried to be used in this study.

The silica content in the bamboo sample was measured by the following procedure. First, bamboo powder was placed in a muffle furnace and burned at $800{ }^{\circ} \mathrm{C}$ for 1 hour to be the ash, then the ash was mixed with sodium hydroxide, and ground into a nickel crucible at a mixing weight ratio of $1: 3$. The crucible was again placed in a muffle furnace, heated at $500^{\circ} \mathrm{C}$ for 1 hour, and then 
cooled to room temperature. After that, the crucible was taken out and soaked in $150 \mathrm{~mL}$ of $1 \mathrm{M}$ hydrochloric acid solution to completely dissolve silica component, and the silicon concentration in the extracted solution was measured with an atomic absorption photometer (PerkinElmer, AAnalyst 200), and the silicon content per $1 \mathrm{~g}$ of bamboo was calculated. Table 1 shows the bamboo powder composition used in this experiment. The moisture content was measured using a moisture meter. In addition, the bamboo powder was burned at $700^{\circ} \mathrm{C}$. in the air atmosphere, and the residual amount was defined as the ash content. Fixed carbon and Volatile matter amount were entrusted to Center for Analytical Instrumentation of Chiba University for measurement. It was found that the silica content per 1 $\mathrm{g}$ of bamboo sample was about $2 \mathrm{mg} / \mathrm{g}$, which was almost same at the silicon content of bamboo in Chiba reported previously about 1.1 to $2.4 \mathrm{mg} / \mathrm{g}$ [4].

Table 1 Composition of the bamboo powder.

\begin{tabular}{|c|c|c|c|c|c|}
\hline \multirow{2}{*}{ Moisture } & \multirow{2}{*}{ Ash } & \multicolumn{3}{|c|}{$\begin{array}{c}\text { Fixed carbon and } \\
\text { Volatile matter }\end{array}$} & \multirow{2}{*}{$\mathrm{Si}$} \\
\cline { 3 - 5 } & & $\mathrm{C}$ & $\mathrm{H}$ & $\mathrm{N}$ & \\
\hline $11 \%$ & $2 \%$ & $44.9 \%$ & $5.4 \%$ & $0.2 \%$ & $2 \mathrm{mg} / \mathrm{g}$ \\
\hline
\end{tabular}

\section{Pyrolysis with $\mathrm{NaOH}$}

Experimental procedure for pyrolysis with $\mathrm{NaOH}$ was shown in Fig. 1. Bamboo powder $(1 \mathrm{~g})$ was placed in a reactor together with sodium hydroxide $(1-3 \mathrm{~g})$ and heated to $300-700{ }^{\circ} \mathrm{C}$ in an electric tube furnace under a nitrogen atmosphere for $0-2 \mathrm{~h}$. After heating, the reactor was cooled to room temperature, then distilled water was added into the reactor, stirred with magnetic stirrer and filtered to recover an insoluble solid and a solution with soluble components in water. The concentration of silicon in the filtrate was measured with an atomic absorption spectrophotometer, and the extracted amount of silica component was calculated. In addition, the gas generated during thermal decomposition was collected in a gas pack, and the amount of generated gas was measured using gas chromatograph (GC-8A, SHIMAZU). The solid residue was dried, and the weight of the residue was measured. The surface shape of the residue was observed with a scanning electron microscope (SEM) (JEOL, JSM6510A) and specific surface areas of the residue were measured by a BET specific surface area measuring equipment (MacsorbModel-12, manufactured by MOUNTECH).

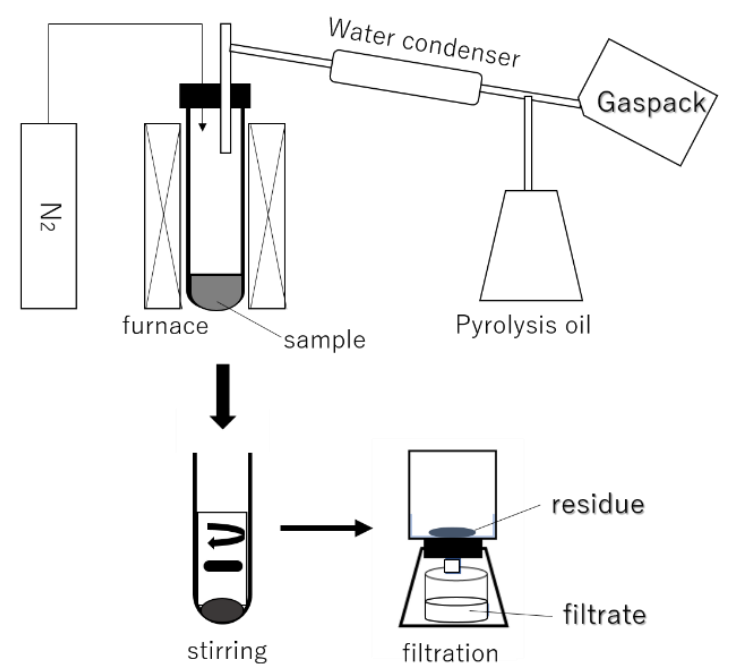

Fig. 1 Schematic diagram of an experimental.

\section{Silica powder preparation}

Preparation of silica powder from the solution extracted from bamboo was carried out by the following procedure. $5 \mathrm{~g}$ of bamboo was pyrolyzed at $500{ }^{\circ} \mathrm{C}$ for 2 $\mathrm{h}$ with addition of $10 \mathrm{~g}$ sodium hydroxide, then cooled to room temperature, and the solid in the reactor was dissolved in $1 \mathrm{M} \mathrm{HCl}$ solution. The obtained extracted silica solution was neutralized by adding a sulfuric acid solution and heated to reduce the amount of water to precipitate the dissolved silica from the solution. After heating, the solution was shaken for 10 minutes, the liquid and the solid were separated by a centrifugation, and the solid was recovered by decantation. The solid was dried, and observation of surface shape and component analysis were carried out with SEM and energy dispersive $\mathrm{X}$-ray spectrometry(EDS).

\section{RESULTS AND DISCUSSION}

Residual weights under each condition are shown in Fig. 2. The heating time is $1 \mathrm{~h}$. As the temperature rises, the residual weight decreases (Fig. 1). When the thermal decomposition temperature is $300{ }^{\circ} \mathrm{C}$, the residual weight is large, and the residue weight tends to be constant when heated above $400{ }^{\circ} \mathrm{C}$. In addition, the residual weight decreases with increasing sodium hydroxide addition. This suggests that an increase in the amount of sodium hydroxide and the thermal decomposition temperature promotes thermal decomposition of bamboo to reduce the weight of the residues. 


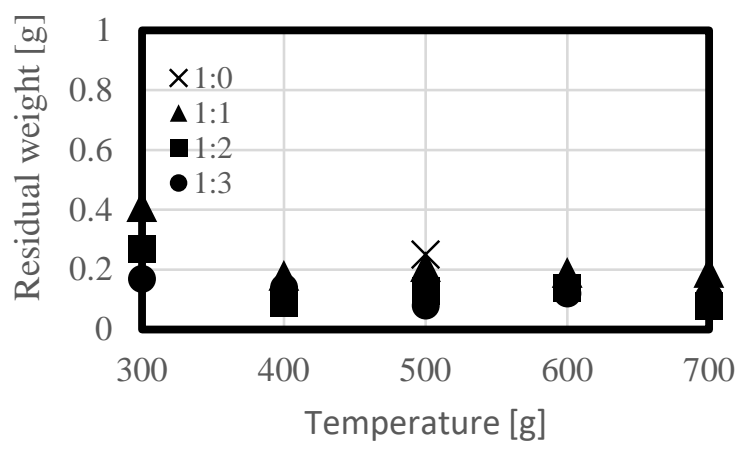

Fig. 2 Residual weights after pyrolysis.

Fig. 3 shows the specific surface area of the residue obtained under each condition. The heating time is $1 \mathrm{~h}$. When the addition amount of sodium hydroxide was 1 $\mathrm{g}$, specific surface areas of the residue is very low, regardless of thermal decomposition temperature. On the other hand, when the addition amount of sodium hydroxide was $2 \mathrm{~g}$ or $3 \mathrm{~g}$, the specific surface areas of the residue increases with increasing temperature, and the residue with about $1500 \mathrm{~m}^{2} / \mathrm{g}$ of specific surface area can be obtained at $600{ }^{\circ} \mathrm{C}$ and $700{ }^{\circ} \mathrm{C}$.

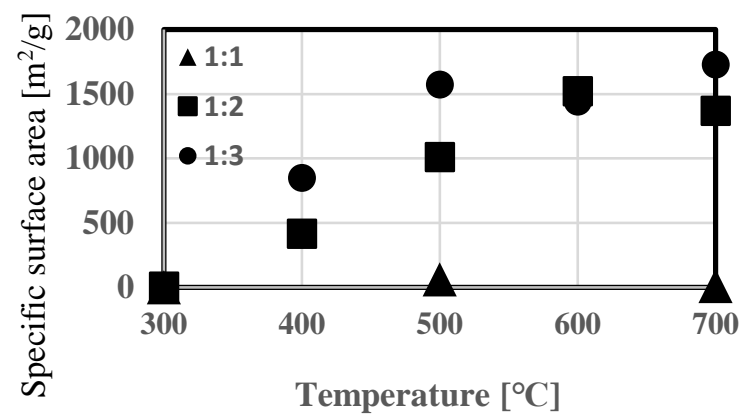

Fig. 3 Specific surface area of the residue after pyrolysis.

Fig. 4 shows SEM photographs of the residue obtained under each condition. The heating time is $1 \mathrm{~h}$. At a thermal decomposition temperature of $500^{\circ} \mathrm{C}$, there is no difference between the residues without $\mathrm{NaOH}$ addition and with $1 \mathrm{~g} \mathrm{NaOH}$ addition (Fig. 4 (a), (b)), whereas a porous shape can be confirmed in the residue with $3 \mathrm{~g}$ $\mathrm{NaOH}$ addition (Fig. 4(c)). On the other hand, with $3 \mathrm{~g}$ $\mathrm{NaOH}$ addition at $300^{\circ} \mathrm{C}$, porous shape was not observed (Fig. 4 (d)). (a)

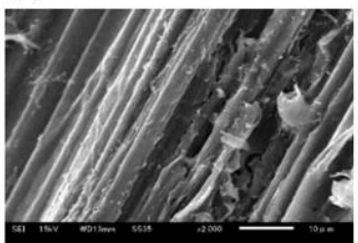

(c).

(b)
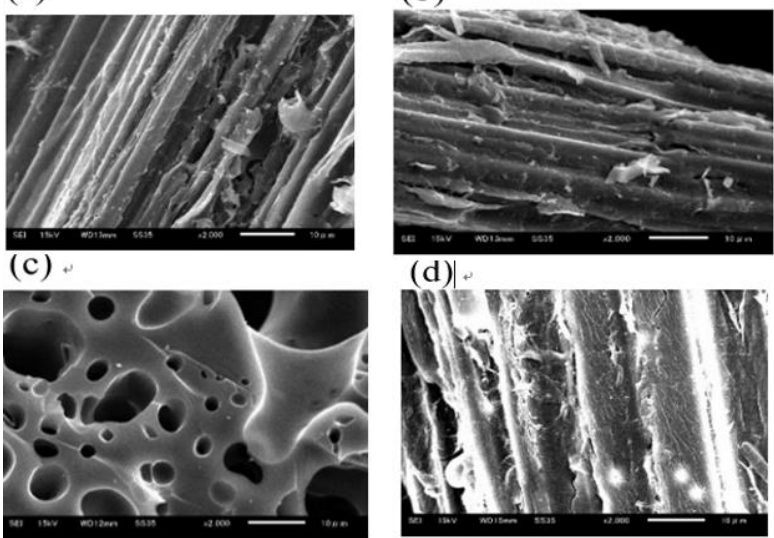

Fig. 4 SEM photograph of the residue (a) without $\mathrm{NaOH}$ not added at $500{ }^{\circ} \mathrm{C}$, (b) with $\mathrm{NaOH} 1 \mathrm{~g}$ addition at 500 ${ }^{\circ} \mathrm{C}$, (c) with $\mathrm{NaOH} 3 \mathrm{~g}$ addition at $500{ }^{\circ} \mathrm{C}$, and (d) with $\mathrm{NaOH} 3 \mathrm{~g}$ addition at $300^{\circ} \mathrm{C}$.

The extracted amount of silicon under each condition is shown in Fig. 5. The heating time is $1 \mathrm{~h}$. When the addition amount of sodium hydroxide was $1 \mathrm{~g}$, silica extraction could not be confirmed, while when sodium hydroxide addition amount is $2 \mathrm{~g}$ or $3 \mathrm{~g}$, regardless of the thermal decomposition temperature, almost silica content in bamboo is extracted.

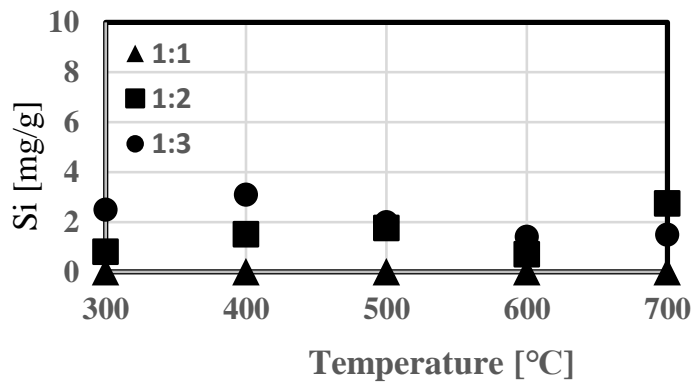

Fig. 5 Extracted amount of silicon under each condition.

SEM photo of the silica powder obtained from bamboo is shown in Fig. 6. It was observed that the powder was gel-like agglomerate. By quantitative analysis using EDS, it was confirmed that the main components of this powder are mainly composed of silicon $(39.5 \%)$ and oxygen $(53.5 \%)$, and the minor contents, sodium and sulfur, derived from sodium hydroxide and sulfuric acid. These are suggested that bamboo-derived silica can be recovered using this process. 


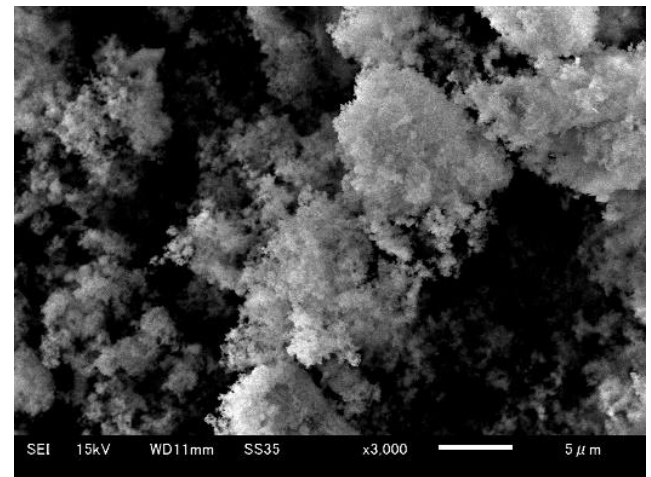

Fig. 6 SEM photograph of the silica powder from bamboo

Generated gas amounts under each condition are shown in Fig. 7. The heating time is $1 \mathrm{~h}$. As the temperature rises and the amount of sodium hydroxide added increased, the amount of generated gas was increased. These results indicate that sodium hydroxide can promote the gasification of bamboo and the promotion is more effective at higher temperature.

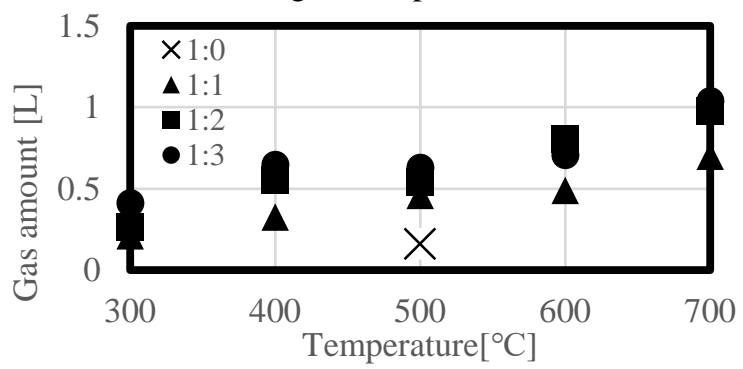

Fig. 7 Gas amounts generated during the pyrolysis.

Fig. 8 shows the amounts of $\mathrm{H}_{2}, \mathrm{CH}_{4}, \mathrm{CO}$ and $\mathrm{CO}_{2}$ generated by pyrolysis with $\mathrm{NaOH}$. Heating time is $1 \mathrm{~h}$. When sodium hydroxide is added, the percent of $\mathrm{H}_{2}$ in the generated gas is about 90 to $95 \%$, regardless of the $\mathrm{NaOH}$ addition and thermal decomposition temperature. $\mathrm{CH}_{4}$ accounted for about 5 to $10 \%$ and the amounts of $\mathrm{CO}$ and $\mathrm{CO}_{2}$ are minor $(<0.5 \%)$, which generated decreased with increasing sodium hydroxide addition. On the other hand, when sodium hydroxide was not added and heated at $500{ }^{\circ} \mathrm{C}, \mathrm{H}_{2}$ and $\mathrm{CH}_{4}$ accounted for about $25 \%$ of the total, $\mathrm{CO}$ and $\mathrm{CO}_{2}$ accounted for about $75 \%$. These results indicate that the addition of sodium hydroxide promotes the generation of gas containing $\mathrm{H}_{2}$ and $\mathrm{CH}_{4}$. (a)

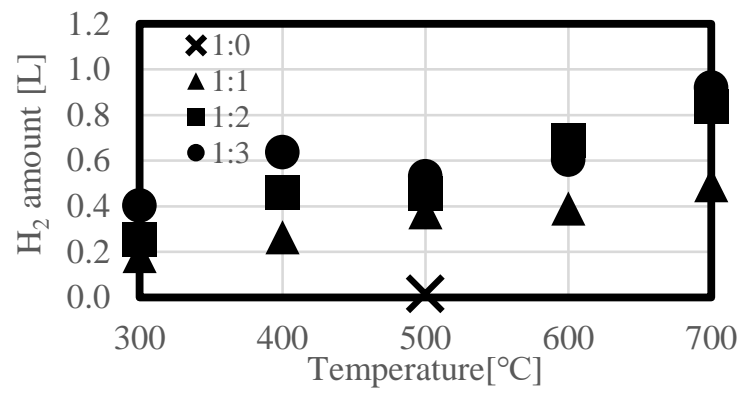

(b)

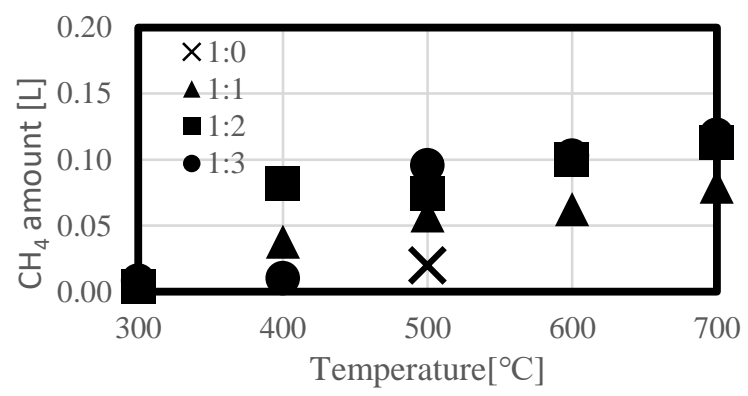

(c)

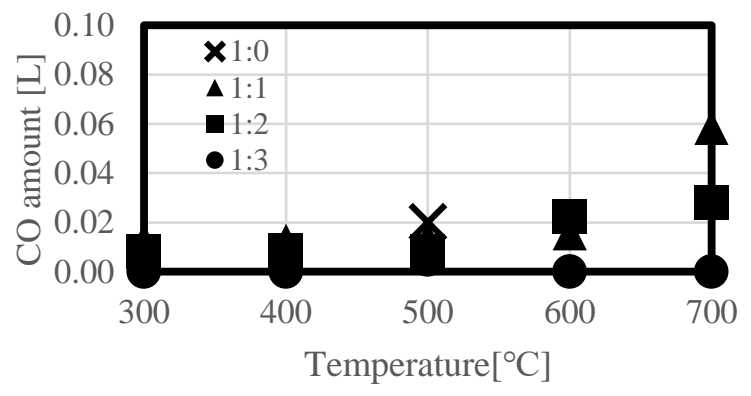

(d)

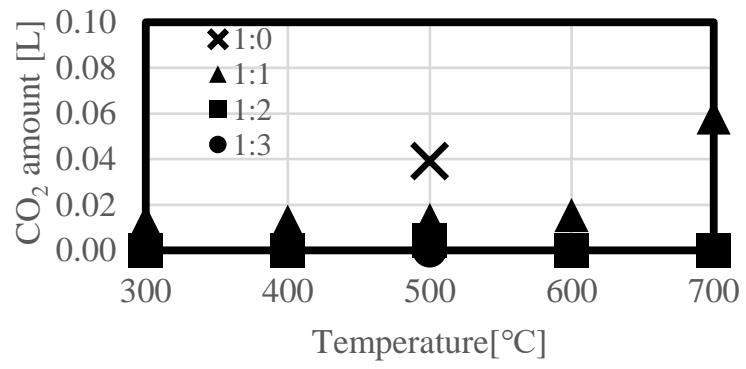

Fig. 8 The amounts of (a) $\mathrm{H}_{2}$, (b) $\mathrm{CH}_{4}$, (c) $\mathrm{CO}$ and (d) $\mathrm{CO}_{2}$ generated during the pyrolysis.

Residual weights during the pyrolysis are shown in Fig. 9. The addition amount of sodium hydroxide was $3 \mathrm{~g}$. When the thermal decomposition temperature was $300{ }^{\circ} \mathrm{C}$, the residue weight was about $0.2 \mathrm{~g}$ with increasing the temperature, the weight was $0.15 \mathrm{~g}$ when it was $400{ }^{\circ} \mathrm{C}$, and the weight was $0.1 \mathrm{~g}$ when it was at higher than $500^{\circ} \mathrm{C}$ or higher. 


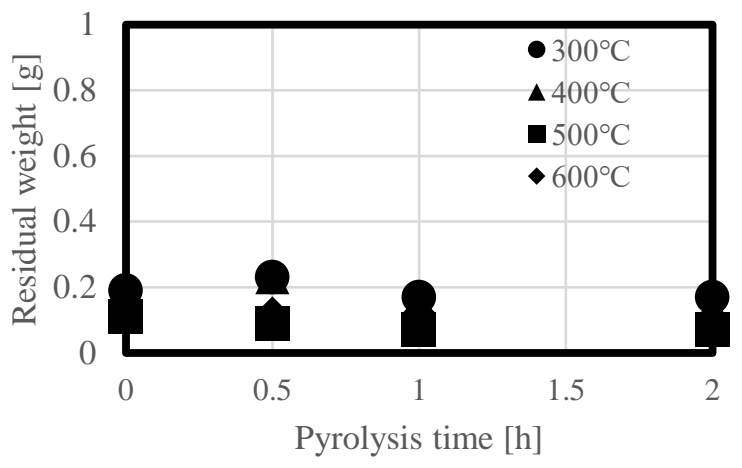

Fig. 9 Residual weights after pyrolysis.

Fig. 10 shows the specific surface area of the residue during pyrolysis. The amount of sodium hydroxide was $3 \mathrm{~g}$. When the thermal decomposition temperature was $300{ }^{\circ} \mathrm{C}$, an increase in the specific surface area could be confirmed after $2 \mathrm{~h}$ pyrolysis. When the thermal decomposition temperature was $400{ }^{\circ} \mathrm{C}$, the specific surface area increased, and became constant after $1 \mathrm{~h}$ pyrolysis. When the thermal decomposition temperatures were $500{ }^{\circ} \mathrm{C}$ and $600{ }^{\circ} \mathrm{C}$, the products with the specific surface area of $1000-1500 \mathrm{~m}^{2} / \mathrm{g}$ could be obtained at the pyrolysis time from $0 \mathrm{~h}$ to $2 \mathrm{~h}$.

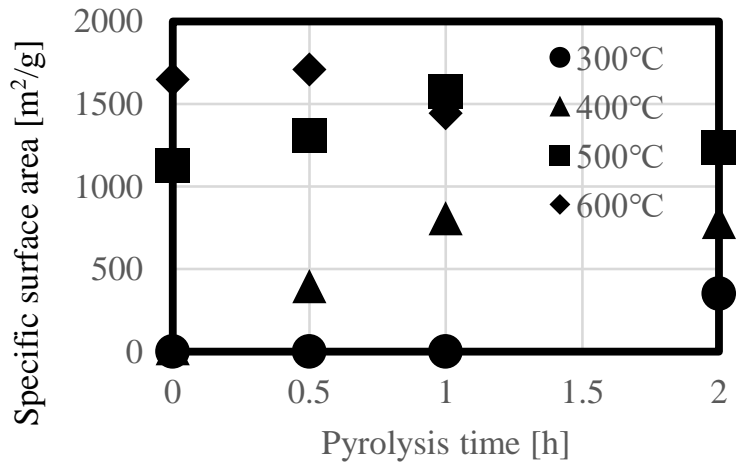

Fig. 10 Specific surface area of the residue after pyrolysis.

The extracted amount of silicon under each condition is shown in Fig. 11. The amount of sodium hydroxide was 3 g. Regardless of the thermal decomposition time, almost silica content in bamboo is extracted. The extraction amount of $\mathrm{Si}$ cannot be measured for 2 hours of pyrolysis time due to equipment trouble.

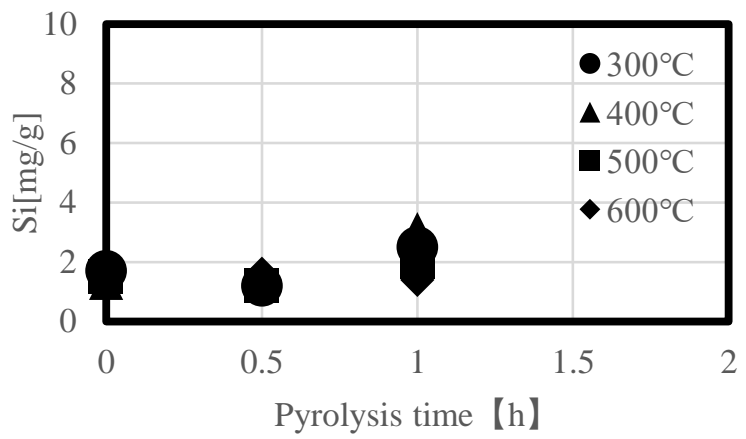

Fig. 11 Extracted amount of silicon under each condition.

Generated gas amounts during pyrolysis are shown in Fig. 12. The amount of sodium hydroxide was $3 \mathrm{~g}$. As the thermal decomposition time increases, the amount of generated gas increases. In the case of the thermal decomposition temperature of $300^{\circ} \mathrm{C}$, the amount of generated gas gradually increased and becomes constant after $1 \mathrm{~h}$ during the pyrolysis. When the thermal decomposition temperature is $400{ }^{\circ} \mathrm{C}-600{ }^{\circ} \mathrm{C}$, the amount of generated gas increases and becomes constant after $0.5 \mathrm{~h}$ pyrolysis. These results indicate that the thermal decomposition temperature promotes the gasification speed of bamboo.

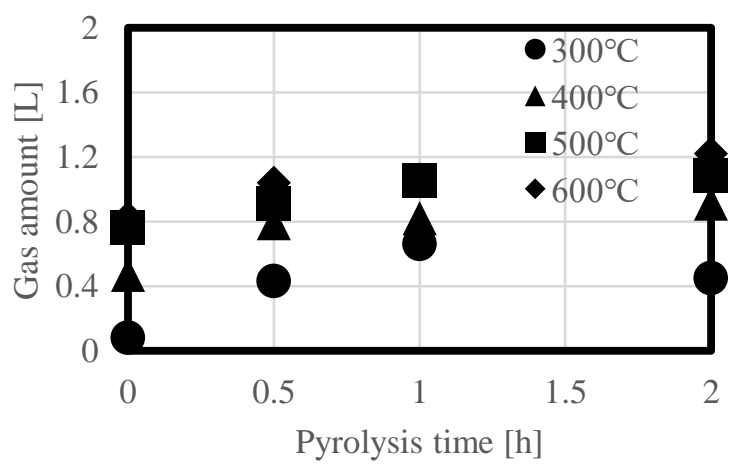

Fig. 12 Gas amounts generated during the pyrolysis.

Fig. 13 shows the amounts of $\mathrm{H}_{2}, \mathrm{CH}_{4}, \mathrm{CO}$ and $\mathrm{CO}_{2}$ generated by during pyrolysis with $\mathrm{NaOH}$. The amount of sodium hydroxide was $3 \mathrm{~g}$. The percent of $\mathrm{H}_{2}$ in the generated gas is about 90 to $95 \%$, regardless of the heating time and thermal decomposition temperature. $\mathrm{H}_{2}$ and $\mathrm{CH}_{4}$ show the same behaviour as in Fig. 13, while $\mathrm{CO}$ and $\mathrm{CO}_{2}$ are minor $(<0.5 \%)$ on all pyrolysis conditions. 
(a)

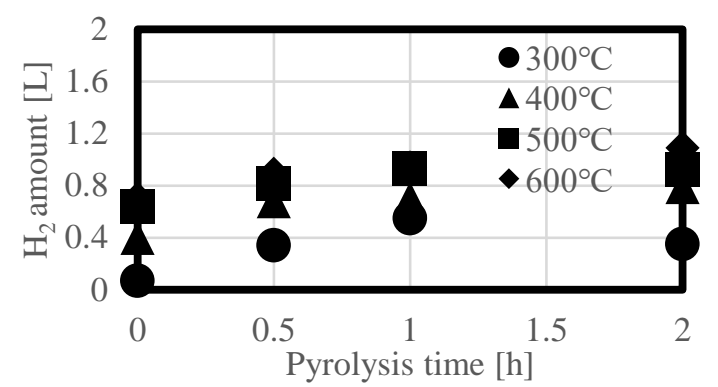

(b)

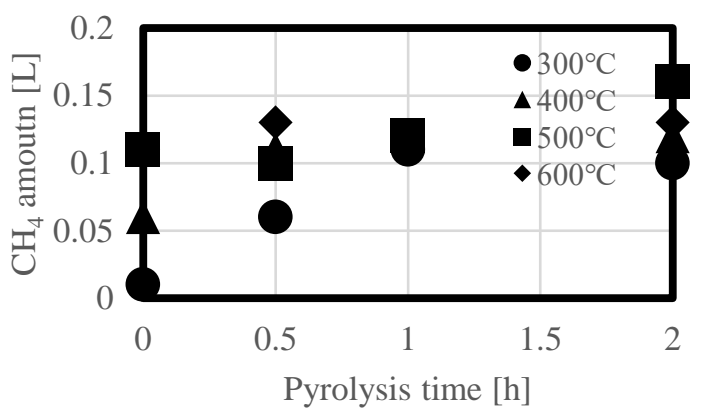

(c)

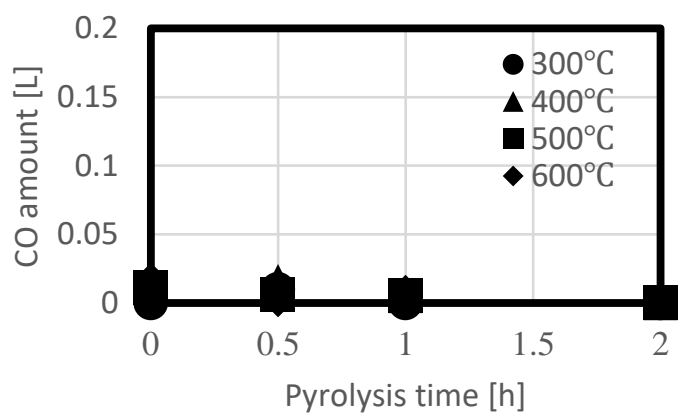

(d)

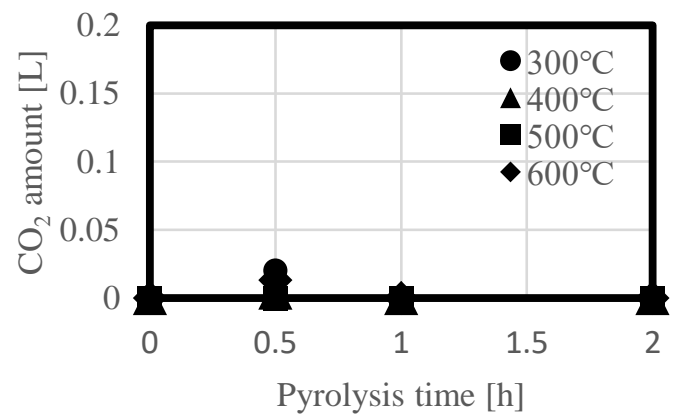

Fig. 13 The amounts of (a) $\mathrm{H}_{2}$, (b) $\mathrm{CH}_{4}$, (c) $\mathrm{CO}$ and (d) $\mathrm{CO}_{2}$ generated during the pyrolysis.

\section{CONCLUSION}

We aimed to develop a new recycling technology for bamboo using alkali hydroxide. By pyrolyzing bamboo using hydroxide under an inert atmosphere, thermal decomposition of organic contents and alkali fusion of silica component inside the bamboo were carried out simultaneously to recover combustible gas, charcoal and silica component.

As a result, it was found that when $1 \mathrm{~g}$ of bamboo was pyrolyzed at higher than $500{ }^{\circ} \mathrm{C}$ with $3 \mathrm{~g} \mathrm{NaOH}$, the almost silica was extracted, a large amount of gas generated, and a carbonized material with specific surface area of about more than $1100 \mathrm{~m} 2 / \mathrm{g}$ was obtained. And it is considered that thermal decomposition is completed in 0.5 hour under this condition.

\section{ACKNOWLEDGMENTS}

The authors acknowledge the financial support from Graduate School of Science and Technology, Chiba University. This work was supported by Takahashi Industrial and Economic Research Foundation.

\section{REFERENCES}

[1] R. Yuvakkumar, V. Elango, V. Rajendran and N. Kannan. 2014. High-purity nano silica powder from rice husk using a simple chemical method. Experimental Nanoscience, 9, 272-281.

[2] C.Igarashi, M.Adachi, ZarZarHlaing and H.Nakagome (Chiba University). Research on hydrogen production by pyrolysis gasification of woody biomass.

[3] K. Konno, Y. Ohba, K.Onoe and T.Yamaguchi. 2008. Preparation of activated carbon having the structure derived from biomass by alkali activation with $\mathrm{NaOH}$, and its application for electric double-layer capacitor. Tanso,231,2-7

[4] K. Yamane, N. Okamori, Y. Imamura, S. Niikawa, and K. Sekiro. 2001. Mokutan oyobi takezumi no kaibun ni fukumareru biryō-gen moto no PIXE bunsekiPIXE. [Analysis of trace elements contained in ash content of charcoal PIXE analysis of trace elements contained in ash content of charcoal and bamboo charcoal.] NMCC Kyōdō kenkyū seika hōkoku, 9, 132-135 